\title{
MICHEL DOSPITAL REFLEXIONA SOBRE LA GÉNESIS Y EL CONTENIDO DE SU LIBRO SIEMPRE MÁS ALLÁ... *
}

1 origen de este libro es una
investigación universitaria
la cual realicé para optar al título de Doctora en Estudios Hispanoamericanos en Francia y que terminé de escribir, siendo docente de francés, en la UNAN Managua, a principios de los años 90. Es una tesis convertida en libro, cuyo destinatario son los estudiantes, los jóvenes, quienes a partir de su propio criterio, rescaten lo que les parezca más relevante del pensamiento y del actuar del General Sandino. Tratando siempre de estar lo más cercano y fiel a la realidad que a él le tocó vivir en ese entonces y que hoy en día conforma la memoria histórica de los nicaragüenses.

Mi llegada a Nicaragua se da en medio de la euforia de la revolución de los años 80. Eran años de esperanzas y de alegría, pero también de guerra y de dolor.

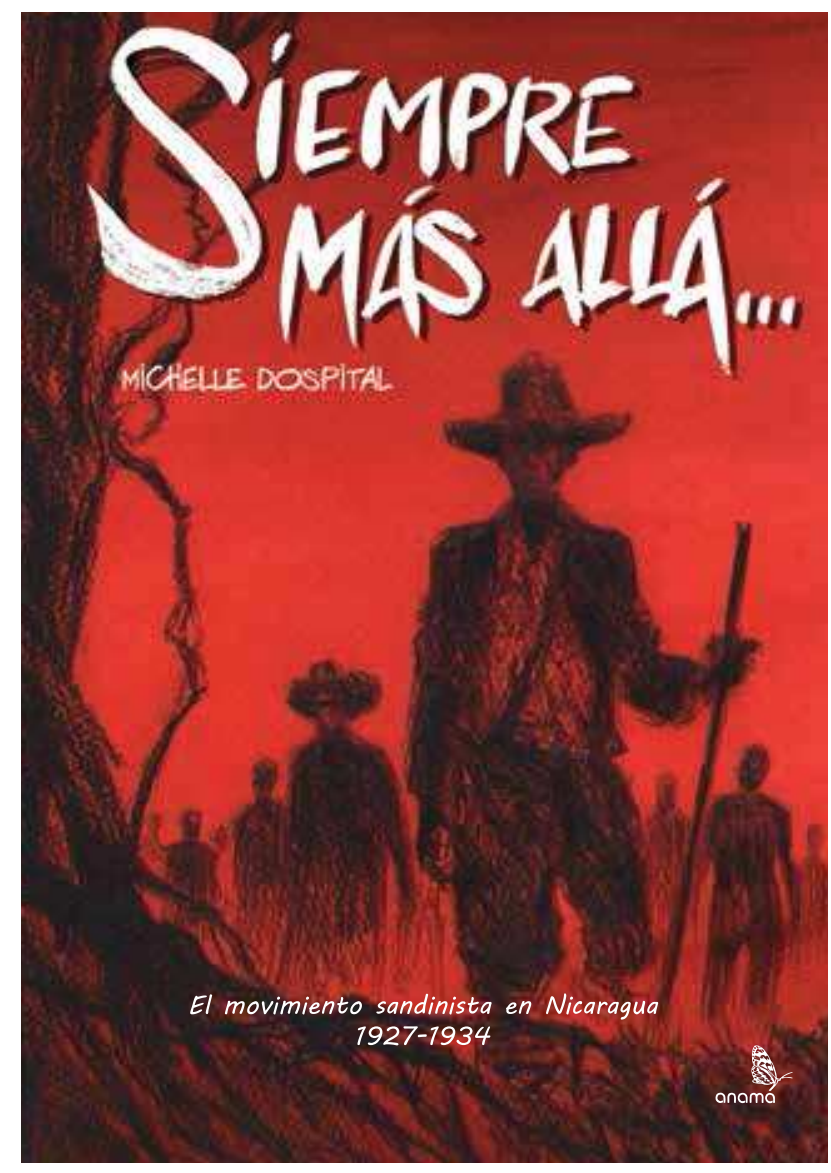
Joven estudiante inmersa en ese remolino, me interesé por la figura enigmática de Augusto C. Sandino y decidí lanzarme a la tarea de demostrar que el movimiento sandinista de liberación nacional en Nicaragua (1927-1934) no se había limitado a una extraordinaria resistencia armada contra la intervención estadounidense, sino también fue portadora de un proyecto político y social audaz, innovador, constructivo para Nicaragua, el cual

sólo podía ser descifrado con un estudio profundo del contexto político, social y económico del país y del continente.

De allí mi búsqueda de fuentes sin explotar hasta la fecha: además de tener el privilegio de acceder a la correspondencia inédita de Sandino, reunida en el archivo del Instituto de Estudios del Sandinismo (IES), consulté los periódicos nicaragüenses de la época,

* Doctora en Historia 
así como la prensa mexicana, costarricense y francesa. Revisé los archivos nacionales de Nicaragua y México; rastreé archivos personales así como testimonios en Nicaragua y en los Estados de Veracruz, Tamaulipas y Yucatán en México.

Opté por un plan temático diferente al habitual esquema cronológico, con la finalidad deponer derelievela evolucióndel proyecto político de Sandino. El propósito era profundizar en ciertos elementos, hasta ese entonces poco conocidos, pero que a mi parecer, eran fundamentales para entender sus planteamientos y reorientaciones.

El libro está compuesto de cuatro capítulos. El primero es "la lucha de liberación nacional" donde se analiza la guerra de guerrillas y la posición de Sandino ante las diferentes modalidades de intervención de los Estados Unidos en Nicaragua. Dado que abundaban los estudios sobre el tema, me limité a hacer un breve resumen. Sin embargo, no es está de más recordar que Sandino, al negarse a firmar la paz en mayo de 1927, se fue a Las Segovia con unos cuantos hombres y logró organizar, en un tiempo relámpago, la resistencia armada contra las tropas de intervención: "el pequeño ejército loco", como lo llamara la poetisa chilena Gabriela Mistral. A pesar de las privaciones y los pocos medios bélicos, este ejército se mantendrá de pie durante 6 años, logrando el retiro de los marines. La primera derrota de las tropas de intervención en el continente.

El segundo capítulo se sitúa desde la perspectiva de "la lucha continental antiimperialista". El movimiento sandinista tuvo un eco internacional muy fuerte. Consagrado por el escritor francés, Henri Barbusse, como General de Hombres libres, Sandino y su ejército popular se convirtieron en un símbolo de la lucha mundial antiimperialista. En América latina se formaron comités de solidaridad, y se integraron decenas de voluntarios a las filas del Ejército Defensor de la Soberanía Nacional (EDSN). Para los intelectuales latinoamericanos, Sandino al defender la libertad de su pueblo, Sandino se convierte en el redentor de la raza indo hispana. Esa identificación continental, representa un pilar fundamental del proyecto político del guerrillero. Durante toda la lucha, insistirá en la necesidad de una unión latinoamericana para impedir cualquier intromisión extranjera. Hace un llamado a una conferencia continental para discutir un proyecto ambicioso de confederación bautizado como "Plan de realización del sueño supremo de Bolívar".

Sandino tendrá muchas presiones de las principales corrientes políticas del continente para que su movimiento se adhiera a esas ideas. En este trbajo, hice énfasis en la compleja relación entre el partido comunista mexicano y Sandino, tratando de explicar cómo dicho partido y por ende el movimiento comunista internacional llegó en 1930 a romper todo lazo con la guerrilla segoviana, acusando a Sandino de no ser más que un caudillo liberal pequeño burgués, traidor al movimiento antiimperialista revolucionario mundial.

Aunque Sandino estaba de acuerdo con el planteamiento de lucha de clase de los comunistas, siempre dejó bien claro que la lucha de liberación en Nicaragua necesitaba de todos los elementos antiimperialistas de la nación, bajo el lema de un frente único y amplio, agregando que al aceptar la ayuda de cualquier partido que sea, no implicaba, de ningún manera compromiso alguno de predicar sus doctrinas.

Este segundo capítulo, pone también de relieve la adhesión del líder Nicaragüense a la Escuela Magnético Espiritual de la 
Comuna Universal (la EMECU). Una corriente espiritista de origen argentino, con fuertes raíces anarcosindicalistas y planteamientos claramente antiimperialistas. Esta corriente tendrá un impacto en la evolución del proyecto sandinista de unión latinoamericana y también en otros aspectos, tratados en los capítulos siguientes.

El eje del tercer capítulo, es la construcción del Estado nacional y la renovación de la vida política del país. Estas reivindicaciones inmutables de Sandino, debilitaron a los dos partidos tradicionales, liberal y conservador y abrieron el camino a la toma de conciencia de la incipiente pera ya influyente clase media urbana, de que cambios estructurales de poder eran imprescindibles para la buena marcha del país. En ese proceso tuvieron un papel fundamental, los llamados "Autonomistas", intelectuales y notables nicaragüenses que sirvieron de enlace entre la guerrilla, los sectores urbanos y el gobierno, en particular para la firma de la paz en febrero de 1933. Este capítulo estudia minuciosamente el último año de vida de Sandino.

Al firmar la paz, Sandino declara que va a hacer otra revolución, ya no armada, sino política. Hasta su asesinato el 21 de febrero de 1934, no dejará de abogar por la reforma de la Guardia Nacional y la creación de un nuevo partido político. Es muy importante subrayar aquí que, a pesar del peligro cada vez más amenazante que representaba la Guardia nacional, y las presiones de ciertos sectores, Sandino se negó a retomar las armas y buscó hasta el final arreglar la situación por medios pacíficos. Insisto mucho en ese último año, porque en general, la imagen consagrada que se tiene de Sandino es: o la de un guerrillero patriota o de un bandolero. Es mucho menos conocido el Sandino, defensor de la paz y de la reconciliación, que ingenuamente o no, entregó su vida por preservar y consolidar la paz recién conseguida y la frágil democracia que imperaba en ese contexto.

Eso me lleva al último capítulo, en cual se analiza el movimiento sandinista desde la perspectiva regional: Las Segovia. Sin el campesinado segoviano, el movimiento sandinista no hubiera existido nunca. Sin Sandino, el campesinado segoviano no hubiera podido defender su dignidad y su tierra. Vuelvo a insistir en el último año de Sandino. Al firmar la paz, el General se instaló en Wiwilí con unos 300 soldados, campesinos desmovilizados $\mathrm{y}$ un resguardo armado de 100 hombres.

Allí empezó a desarrollar varios proyectos socio-económicos, entre ellos unas cooperativas agrícolas de auto-gestión. El lugar escogido por Sandino era estratégico: estaba ubicado en la frontera agrícola. Al invitar al campesinado a instalarse en las tierras nacionales, no solamente ofrecía trabajo a los excombatientes sino también defendía la vía campesina de producción contra el avance del latifundio.

Al llegar al final de este capítulo, se evidencia que el asesinato de Sandino era una necesidad entre ciertos sectores del poder político, no tanto por el potencial militar que aún representaba, sino por su ascendencia política, moral y social. Ponía en peligro los pilares del país: los dos partidos tradicionales, el gran capital agrario y por supuesto la Guardia Nacional y su nuevo jefe, el general Somoza.

Para finalizar mencionaré dos temas transversales fundamentales para identificar a Sandino, los cuales desde el principio me impulsaron a dedicar tantos años a ese gran hombre y a sus hazañas. El primero está relacionado con una pregunta: 
¿Qué era Sandino? ¿Revolucionario, reformista, socialista, comunista, liberal, anarcosindicalista, masón, espiritualista o espiritista? Sandino no era un teórico de la política. Fue a partir de la práctica organizativa de la lucha armada desde la cual fue elaborando su proyecto político.

Se inspiró en las grandes corrientes políticas, sociales, esotéricas y teosóficas de la época, adaptando las ideas a la situación propia de su país y de su base social. El proyecto sandinista no nació de la nada, pero tampoco se alineó a una ideología exclusiva. De allí que todas las interpretaciones y críticas fueron y siguen siendo posibles.

De manera particular, considero que el movimiento sandinista fue un movimiento armado, político y social, revolucionario y original en la Nicaragua y la América latina de las décadas del veinte y treinta del pasado siglo $\mathrm{XX}$.
El segundo punto, tiene que ver con la ética. La armonía constante que existió entre los principios y la actuación del líder nicaragüense. Por eso insistí tanto en el último año de su vida, el cual es revelador de la naturaleza profunda, tanto del hombre como del dirigente político y militar. Al firmar la paz en 1933, Sandino hubiera podido exigir un puesto en el gobierno o irse al extranjero. Sin embargo, rechazó toda prebenda y compartió la suerte de su base social al instalarse en Las Segovia. Esa simbiosis entre Sandino y el campesinado segoviano fue el elemento esencial del éxito del movimiento de liberación, pero también la causa de su trágico final.

Mi trabajo no es exhaustivo. Existen otros estudios valiosos y ojalá sigan saliendo más para poder llegar a un conocimiento y reconocimiento cada más amplio y profundo del carismático e insólito Augusto Nicolás Calderón Sandino. 